\title{
A Study on Herbal Finish to Prevent Bed Sore Using Mangifera indica and Triphala Dried Fruit
}

\author{
Kiruthika Deivasigamani, ${ }^{1}$ Siva Kumar Kolandaivel, ${ }^{2}$ and Kavitha Krishnamoorthi ${ }^{1}$ \\ ${ }^{1}$ Kumaraguru College of Technology, Coimbatore 641049, India \\ ${ }^{2}$ Angel College of Engineering and Technology, Tirupur 641665, India \\ Correspondence should be addressed to Kavitha Krishnamoorthi; s_kavishna@yahoo.co.in
}

Received 31 July 2014; Accepted 11 November 2014; Published 1 December 2014

Academic Editor: Ajoy K. Sarkar

Copyright ( 2014 Kiruthika Deivasigamani et al. This is an open access article distributed under the Creative Commons Attribution License, which permits unrestricted use, distribution, and reproduction in any medium, provided the original work is properly cited.

\begin{abstract}
"Bed sores" owe their name to the observation that patients who were bedridden and not properly repositioned would often develop ulcerations or sores on their skin, typically over bony prominences. These bed sores, which result from prolonged pressure, are also called "decubitus ulcers," "pressure sores," "skin breakdown," and "pressure ulcers." They are associated with adverse health outcomes and high treatment costs. This study focuses on developing herbal finish to prevent bed sores. For this purpose, functional finishing was utilized to produce a bedsore preventing fabric. Plain weave cotton fabric was dyed by using herbal extracts, dried, and then cured. Two samples in different ratios (1:2 and 2:1) of two herbal extracts (Mangifera indica and Triphala dried fruits) were prepared with and without binder (chitosan). Air permeability, wicking ability, Drop Test for absorbency, and antibacterial properties were examined for those samples. Based on the results, fabric dyed with Mangifera indica and Triphala dried fruits in the ratio of $2: 1$ with chitosan is determined as the most promising combination for the final product.
\end{abstract}

\section{Introduction}

The skin is a large barrier organ that protects the human body from environmental hazards (heat, cold, chemicals, mechanical forces, etc.) and maintains the integrity of the body, whereas the clothing system provides extra layer(s) of barrier to enhance the aesthetic, thermophysiological, and sensorial comfort of the wearer [1]. However, direct contact and interactions between textiles and skin may cause reactions, even damage or diseases [2] (see Figure 1).

Bed sores can result from one period of sustained pressure on the skin; however, most bed sores probably occur as a result of repeated incidents of blood flow interruption without adequate time for recovery. In fact, low pressure endured for long periods of time is believed to be more significant in producing pressure ulcers than higher pressure for shorter durations. The role that textiles play in the prevention and formation of these injuries is examined.

\section{Materials and Methodology}

2.1. Fabric Particulars. Plain weave cotton fabric with $60 \mathrm{~s}$ yarn count, EPI: 88 , and PPI: 86.

\subsection{Herb Particulars. See Table 1.}

2.3. Methodology. The selected herbs were dried in sunshade and grinded. Methanol extract of the herbs was obtained and tested for antibacterial and wound healing property. Chitosan was then diluted with citric acid. Scoured and bleached fabric was padded, dried, and cured with and without binder. Fabric was then tested for its antibacterial and wound healing property, washing fastness, air permeability, wicking ability, and water absorbency. Finally its results were discussed (see Figure 2).

2.4. Finishing Agents. Methanol extract of Mangifera indica and Triphala dried fruits (Terminalia chebula, Terminalia bellerica, and Emblica officinalis) has the antibacterial and 
TABLE 1

\begin{tabular}{|c|c|c|c|c|}
\hline SI number & & Botanical name & Common name & Chemical constituents \\
\hline (1) & & Mangifera indica [3] & Mango (leaf) & $\begin{array}{l}\text { C-Glucoside xanthone mangiferin, tannins, alkaloids, glycosides, } \\
\text { terpenoids, flavonoids, amino acids, proteins, euxanthin acid, and } \\
\text { euxanthon. }\end{array}$ \\
\hline \multirow{4}{*}{ (2) } & & & & Triphala dried fruits \\
\hline & (a) & Terminalia chebula [4] & Chebulic myrobalan & $\begin{array}{l}\text { Tannins, chebulagic acid, chebulinic acid, ellagic acid, a tannin } \\
\text { terchebin, an ellagitannin terchebulin, syringic acid, and gallic acid. }\end{array}$ \\
\hline & (b) & Terminalia bellerica [5] & Belleric myrobalan & $\begin{array}{l}\text { Hexahydroxydiphenic acid ester, } \beta \text {-sitosterol, gallic acid, ellagic acid, } \\
\text { ethyl gallate, galloyl glucose, chebulagic acid, mannitol, glucose, } \\
\text { galactose, and rhamnose. }\end{array}$ \\
\hline & (c) & Emblica officinalis [6] & Indian gooseberry/amla & $\begin{array}{l}\text { Organic acids_ascorbic acid, vitamin, tannin; bioflavonoids-quercetin, } \\
\text { kaempferol; polyphenols-gallic acid; cytokinins_zeatin. }\end{array}$ \\
\hline
\end{tabular}

TABLE 2

\begin{tabular}{|c|c|c|c|c|}
\hline Samples & M1 & M2 & $\mathrm{C} 1$ & $\mathrm{C} 2$ \\
\hline Mangifera indica extract & $2 \%$ & $1 \%$ & $2 \%$ & $1 \%$ \\
\hline Triphala dried fruits extract & $1 \%$ & $2 \%$ & $1 \%$ & $2 \%$ \\
\hline Chitosan diluted with citric acid (fabric dipped for $30 \mathrm{~min}$ ) & * & $*$ & $6 \%$ & $6 \%$ \\
\hline MLR ratio (fabric dipped for $2 \mathrm{hrs}$ ) & $1: 20$ & $1: 20$ & $1: 20$ & $1: 20$ \\
\hline Drying (for $5 \mathrm{~min}$ ) & $80^{\circ} \mathrm{C}$ & $80^{\circ} \mathrm{C}$ & $80^{\circ} \mathrm{C}$ & $80^{\circ} \mathrm{C}$ \\
\hline Curing (for $2 \mathrm{~min}$ ) & $150-180^{\circ} \mathrm{C}$ & $150-180^{\circ} \mathrm{C}$ & $150-180^{\circ} \mathrm{C}$ & $150-180^{\circ} \mathrm{C}$ \\
\hline
\end{tabular}

* denotes that samples M1 and M2 are not treated with Chitosan.

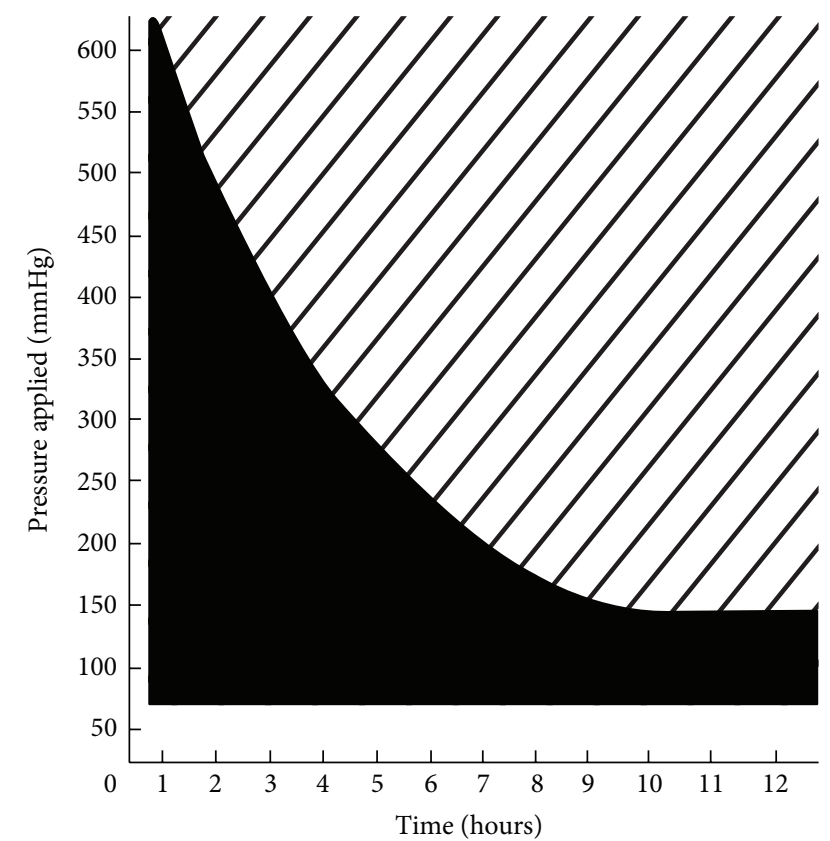

Ulceration No ulceration

FIgURE 1: Time versus pressure curve for tissue breakdown in a canine model [2].

wound healing property. 25 grams of herbal powder is dissolved in $100 \mathrm{~mL}$ of methanol and then it is concentrated into $50 \mathrm{~mL}$ using Soxhlet apparatus to obtain the extract.

\subsubsection{Recipe. See Table 2.}

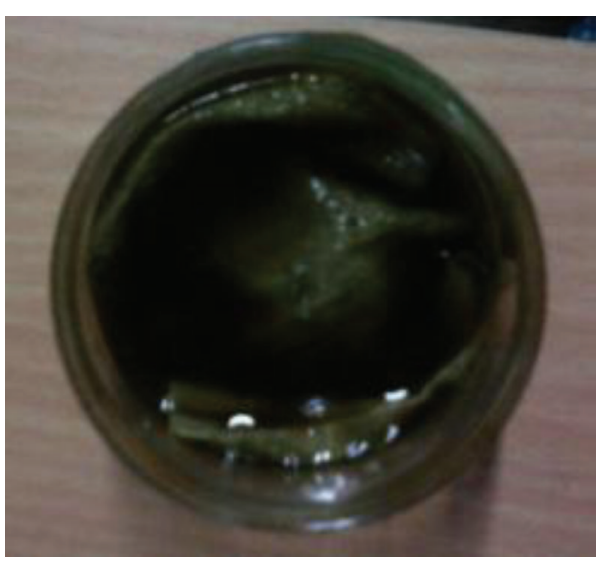

FIgURE 2: Herbal extract along with binder.

\section{Results and Discussion}

3.1. Wickability. Fabric specimen is cut into the size of $12^{\prime \prime} \times$ $1^{\prime \prime}$ and hung over the stand. A beaker is filled with tinted distilled water. The lower end of the fabric strip is made to touch the water in such a way that half an inch height of the fabric is kept immersed inside the water. To keep the fabric strip in straight configuration a load of $10 \mathrm{~g}$ of weight is applied to the bottom of it. The rise of the water level in the fabric is measured after 10 minutes.

The wickability of treated and untreated plain weave cotton fabric samples was assessed by time for wetting. The vertical wicking test results are shown the table. 
TABLE 3: Wickability result of the treated and untreated fabric samples.

\begin{tabular}{lcc}
\hline SI number & Type of the sample & Wicking height in centimeters \\
\hline 1 & Bleached fabric & 5 \\
2 & Sample 1-M1 & 7.5 \\
3 & Sample 2-M2 & 7.5 \\
4 & Sample 3-C1 & 9 \\
5 & Sample 4-C2 & 9.5 \\
\hline
\end{tabular}

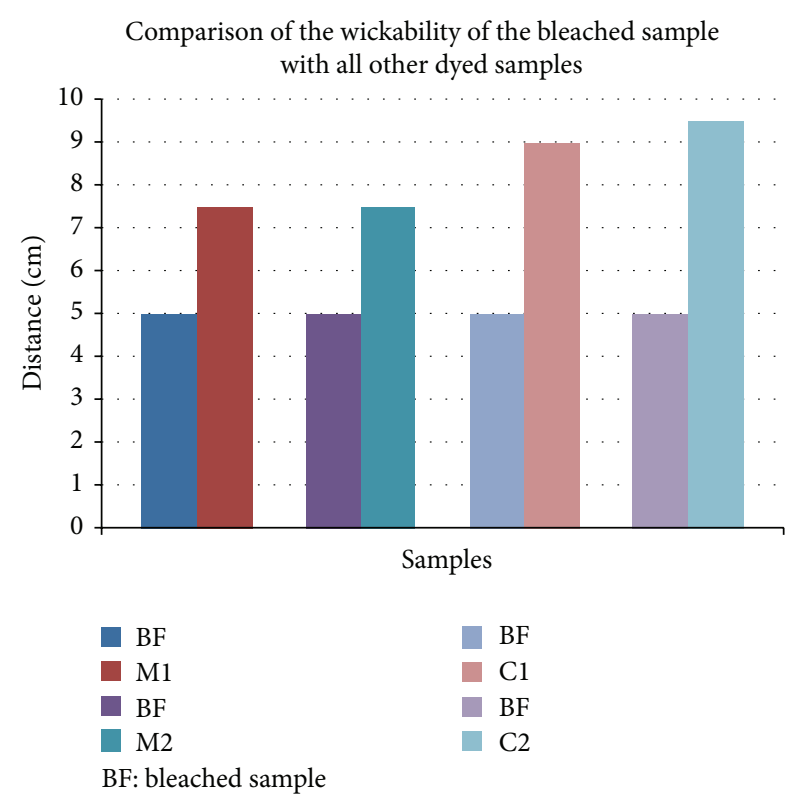

Figure 3: Comparison of wickability results of the treated and untreated samples.

3.1.1. Wickability Test Results. The wicking property of the finished fabric has been improved for all the samples when compared with the bleached fabric. Wickability of the samples treated with chitosan is highly increased (see Table 3 and Figure 3).

3.2. Drop Test. It is used to measure the time taken for the fabric to absorb a drop of water. The absorption rate of fabric changes as per the thickness of the fabric, weave structure, and finishes applied to the fabric.

3.2.1. Drop Test Results. The time taken to absorb a drop of water is decreased in the finished samples when compared with the bleached sample. This shows that the absorbency is increased after finishing. Comparing to all the four samples sample 3-C1 showed good absorbency (see Table 4 and Figure 4).

3.3. Air Permeability. It is the volume of air measured in cubic $\mathrm{cm}$ passed per second through $1 \mathrm{~cm}^{2}$ for the fabric at a pressure one $\mathrm{cm}$ head of water. It is measured by using air permeability tester. The air permeability of a fabric is a measure of how well it allows the passage of air through it.

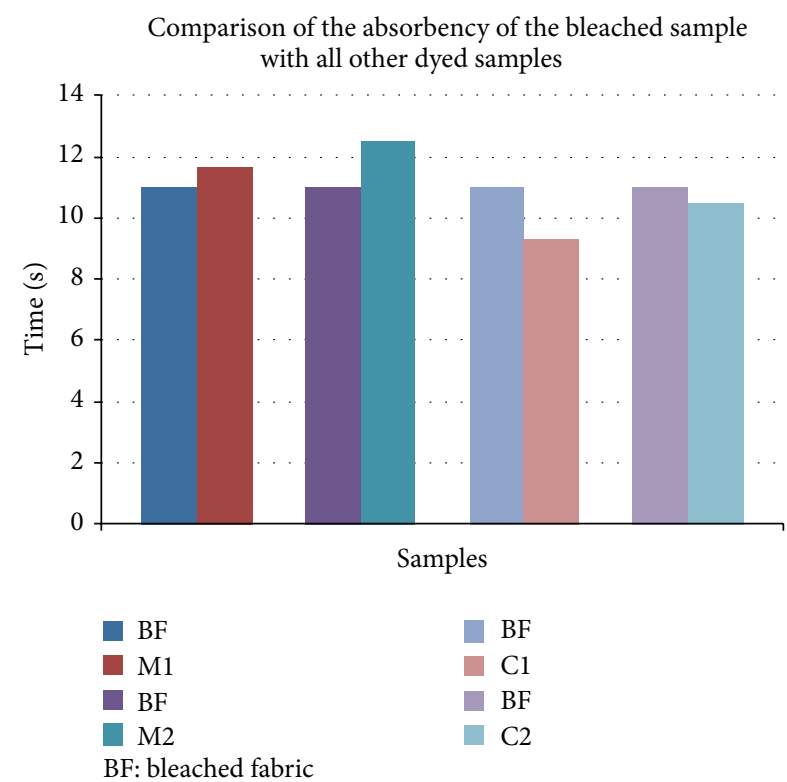

Figure 4: Comparison of Drop Test results of the treated and untreated fabric samples.

3.3.1. Air Permeability Test to Various Fabrics. Air permeability is an important factor in the performance of textile materials used to provide an indication of the breathability of coated fabrics. The air permeability of treated and untreated plain weave of cotton fabric samples was assessed. Consider

$$
\text { Air permeability }=\frac{1000 * r}{3600 * A},
$$

where $r$ rotameter reading and $A=4 \mathrm{~cm}^{2}$ (testing area).

3.3.2. Air Permeability Test Results. Air permeability of the plain weave cotton fabric is high in all the treated samples compared to the untreated samples (see Table 5 and Figure 5).

\subsection{Antibacterial Test}

3.4.1. Results of Antibacterial Activity of the Herbal Extracts (Kirby-Bauer Disk Diffusion Susceptibility Test). Mangifera indica and Triphala dried fruits have antibacterial activity against Staphylococcus aureus (see Table 6 and Figure 6).

3.4.2. Results of Antibacterial Activity of Textile Fabric. Only sample 1-M1 and sample 3-C1 have antibacterial activity against Staphylococcus aureus (see Table 7 and Figure 7).

3.5. Wound Healing Test: Angiogenic Activity of the Herbal Extract and Herbal Based Textile Fabric. The herbal extract of Triphala dried fruits containing compounds with angiogenesis modulating properties showed strong angiogenic activity in CAM (chorioallantoic membrane) treated with herbal extract, by increasing the size and number of blood vessels as compared to the control.

The herbal based treated cloth $\mathrm{C} 1$ showed better angiogenic activity in CAM. The size and number of blood 
TABLE 4: Drop Test result for the treated and untreated fabric samples.

\begin{tabular}{lccccc}
\hline \multirow{2}{*}{ SI number } & Name of the samples & \multicolumn{3}{c}{ Time taken to absorb a drop of water in seconds } \\
& & Trial 1 & Trial 2 & Trial 3 & 10.84 \\
\hline 1 & Bleached fabric & 11.36 & 10.91 & 12.50 & 11.03 \\
2 & Sample 1-M1 & 11.25 & 11.29 & 12.08 & 11.68 \\
3 & Sample 2-M2 & 12.62 & 12.89 & 9.33 & 12.53 \\
4 & Sample 3-C1 & 9.56 & 9.03 & 10.67 & 10.46 \\
5 & Sample 4-C2 & 10.36 & 10.37 & 9.30 \\
\hline
\end{tabular}

TABLE 5: Average value evaluation of air permeability.

\begin{tabular}{lcccccc}
\hline SI number & Name of the samples & Trial 1 & $\begin{array}{c}\text { Rotameter reading } \\
\text { Trial 2 }\end{array}$ & AVG & $\begin{array}{c}\text { Air permeability } \\
(\mathrm{cc} / \mathrm{sec} / \mathrm{cm})^{2}\end{array}$ & $\begin{array}{c}\text { Air permeability } \\
(\mathrm{cc} / \mathrm{sec} / \mathrm{cm})^{2} / 60\end{array}$ \\
\hline 1 & Bleached fabric & 242 & 304 & 273 & 18.9 & 0.315 \\
2 & Sample 1-M1 & 376 & 344 & 360 & 25 & 0.416 \\
3 & Sample 2-M2 & 450 & 410 & 430 & 36.8 & 0.496 \\
4 & Sample 3-C1 & 360 & 370 & 365 & 25.3 & 0.422 \\
5 & Sample 4-C2 & 480 & 490 & 485 & 33.6 & 0.561 \\
\hline
\end{tabular}

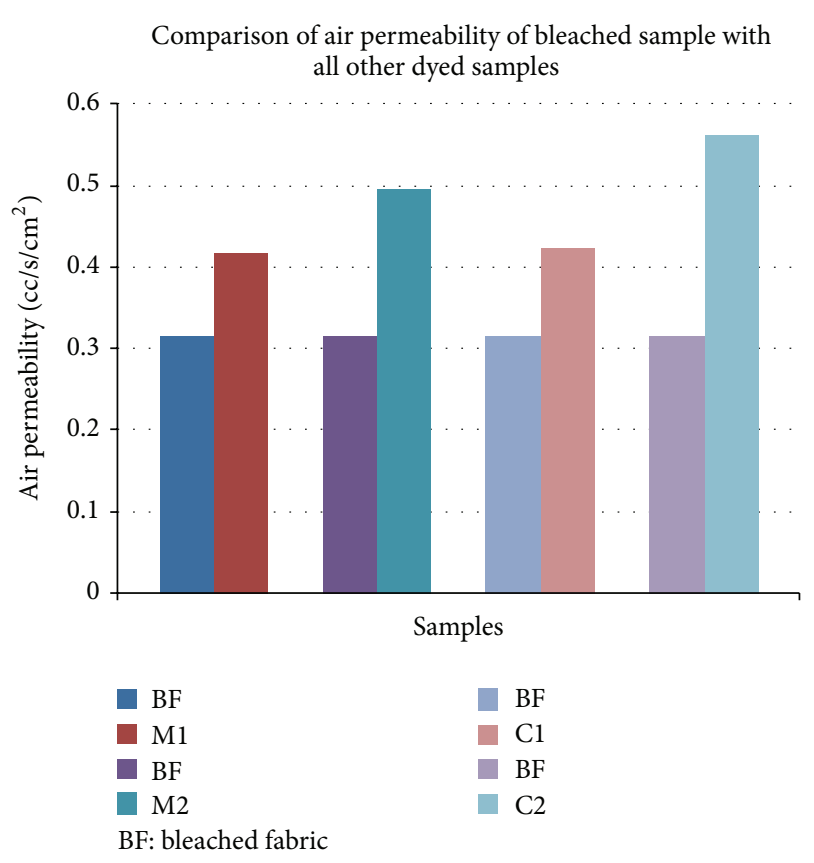

Figure 5: Average value evaluation of air permeability.

vessels were high compared to control egg treated with saline (see Table 8 and Figure 8).

\subsection{Washing Fastness Test}

3.6.1. Results of Washing Fastness Test for Its Antibacterial Property. Only sample $\mathrm{C} 1$ has the washing fastness of antibacterial property for up to 3 washes, which shows that chitosan acts as a binder up to certain level (see Table 9).

3.6.2. Results of Washing Fastness Test for Its Wound Healing Property. Only sample $\mathrm{C} 1$ has the washing fastness for wound
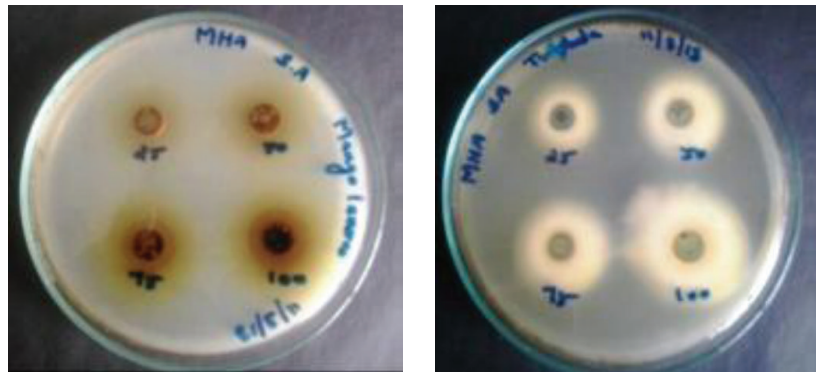

FIgURE 6: Antibacterial activity of the herbal extract.

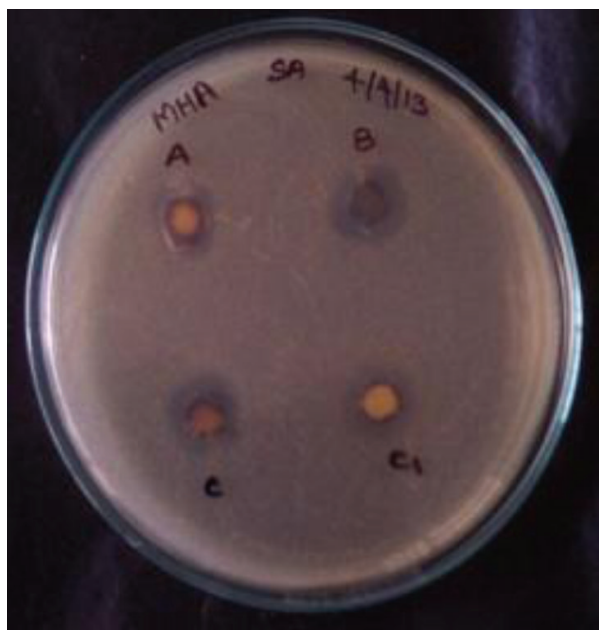

Figure 7: Antibacterial test of the treated samples.

healing property for more than 10 washes, which shows that chitosan acts as a binder up to certain level (see Table 10). 
TABLE 6: Antibacterial activity of the herbal extract.

\begin{tabular}{|c|c|c|c|c|c|c|c|c|}
\hline Plant extract & & Staphy & is aureus & & & Pseudom & eruginose & \\
\hline Concentration & $25 \mu \mathrm{L}$ & $50 \mu \mathrm{L}$ & $75 \mu \mathrm{L}$ & $100 \mu \mathrm{L}$ & $25 \mu \mathrm{L}$ & $50 \mu \mathrm{L}$ & $75 \mu \mathrm{L}$ & $100 \mu \mathrm{L}$ \\
\hline Mangifera indica & Nil & Nil & $6 \mathrm{~mm}$ & $11 \mathrm{~mm}$ & Nil & Nil & $8 \mathrm{~mm}$ & $12 \mathrm{~mm}$ \\
\hline Triphala dried fruits & $11 \mathrm{~mm}$ & $13 \mathrm{~mm}$ & $15 \mathrm{~mm}$ & $21 \mathrm{~mm}$ & $10 \mathrm{~mm}$ & $12 \mathrm{~mm}$ & $14 \mathrm{~mm}$ & $16 \mathrm{~mm}$ \\
\hline
\end{tabular}

TABLE 7: Antibacterial activity of textile fabric coated with the herbal extract.

\begin{tabular}{|c|c|c|c|}
\hline SI number & Name of the samples & Staphylococcus aureus & Pseudomonas aeruginosa \\
\hline 1 & Sample 1-M1 & $3 \mathrm{~mm}$ & Nil \\
\hline 2 & Sample 2-M2 & Nil & Nil \\
\hline 3 & Sample 3-C1 & $11 \mathrm{~mm}$ & Nil \\
\hline \multirow[t]{2}{*}{4} & Sample 4-C2 & Nil & Nil \\
\hline & Control (chloramphenicol) & $24 \mathrm{~mm}$ & $10 \mathrm{~mm}$ \\
\hline
\end{tabular}

TABLE 8: Angiogenic activity of herbal extract and herbal based textile fabric.

\begin{tabular}{lc}
\hline Sample name & Number of blood vessel formation \\
\hline Triphala dried fruits & 12 \\
M1 & Nil \\
M2 & Nil \\
C1 & 16 \\
C2 & Nil \\
Control & 8 \\
\hline
\end{tabular}

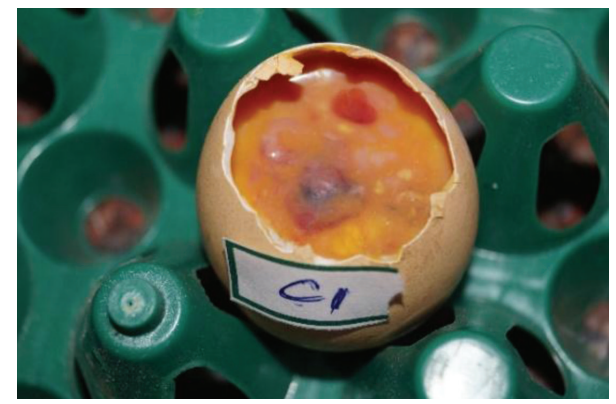

Figure 8: Wound healing test of the treated sample C1.

TABLE 9: Antibacterial activity of fabric coated with the herbal extract (for washing fastness).

\begin{tabular}{lcc}
\hline SI number & Name of the sample & Staphylococcus aureus \\
\hline 1 & C1, up to 3 washes & $3 \mathrm{~mm}$ \\
2 & $\mathrm{C} 1$, up to 5 washes & $\mathrm{Nil}$ \\
& Control (chloramphenicol) & $24 \mathrm{~mm}$ \\
\hline
\end{tabular}

\section{Conclusion}

In this work, herbal based antibacterial finish was applied to the cotton fabric. Extracts of Mangifera indica and Triphala dried fruit were applied to the fabric in two different ratios with and without the binder chitosan.

Based on the tests conducted, the obtained results were shown in the tables and figures. According to the results,
TABLE 10: Wound healing activity of fabric coated with the herbal extract (for washing fastness).

\begin{tabular}{lc}
\hline Sample name & Number of blood vessel formation \\
\hline C1, up to 3 washes & 14 \\
C1, up to 5 washes & 13 \\
C1, up to 10 washes & 10 \\
Control & 8 \\
\hline
\end{tabular}

the treated samples $\mathrm{M} 1$ and $\mathrm{C} 1$ showed good antibacterial property and sample $\mathrm{C} 1$ showed excellent wound healing property. The samples treated with chitosan have high wickability and water absorbency properties. Air permeability in the bleached fabric is low and it has been increased in all the treated samples. Washing fastness result shows that the fabric treated with chitosan shows antibacterial property for up to 3 washes and wound healing property for more than 10 washes.

So it is concluded that sample $\mathrm{Cl}$ has much better properties for preventing bed sore. The herbal extract of Mangifera indica shows good antibacterial property when applied to the fabric compared to the Triphala dried fruits and chitosan has good binding property. And it is suggested that this fabric could be used for preventing bed sore and also for other applications where antibacterial finish is required. And also it gives cost-wise benefit to people. In addition, it is environment friendly.

\section{Conflict of Interests}

The authors declare that there is no conflict of interests regarding the publication of this paper.

\section{References}

[1] N. Bergstrom, A. Bennett, C. E. Carlson et al., Pressure Ulcer Treatment: A Critical Practice Guideline, AHCPR, 1995.

[2] N. C. Petersen and S. Bittmann, "The epidemiology of pressure sores," Scandinavian Journal of Plastic and Reconstructive Surgery, vol. 5, no. 1, pp. 62-66, 1971.

[3] N. Neelima, M. Sudhakar, M. B. Patil, and B. V. S. Lakshmi, "Anti-ulcer activity and HPTLC analysis of Mangifera indica L. 
leaves," International Journal of Pharmaceutical and Phytopharmacological Research, vol. 1, no. 4, pp. 146-155, 2012.

[4] W. D. Schindler and P. J. Hauser, Chemical Finishing of Textile, Woodhead, 2004.

[5] A. K. Meena, A. Yadav, U. Singh et al., "Evaluation of physicochemical parameters on the fruit of Terminalia bellirica roxb," International Journal of Pharmacy and Pharmaceutical Sciences, vol. 2, supplement 2, p. 97, 2010.

[6] N. K. Savala, P. N. Haritha, and M. L. Narasu, "Haematological studies of Emblica officinalis formulation on wistar rats," International Journal of Medical and Health Sciences, vol. 1, no. 2, pp. 29-34, 2012. 

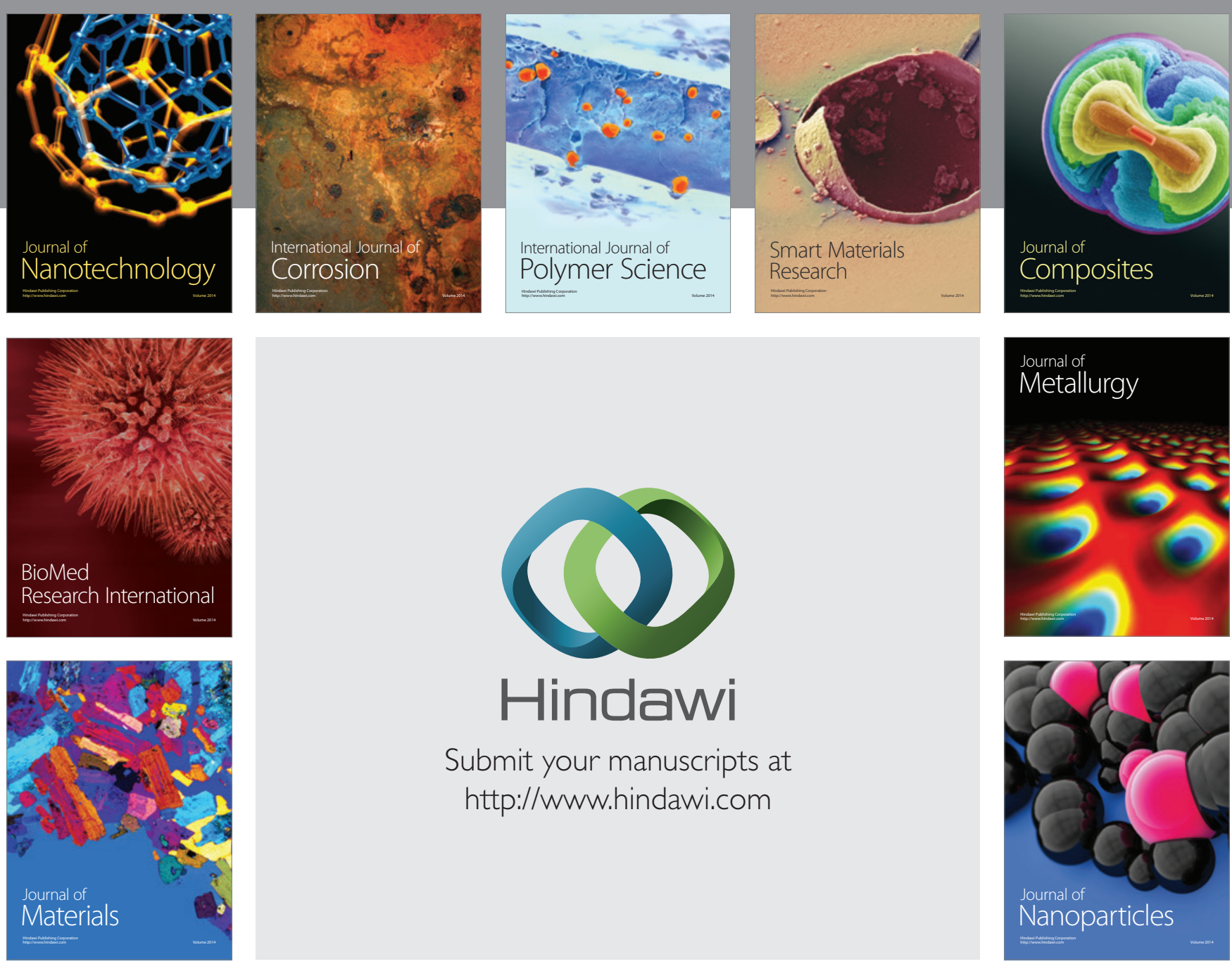

Submit your manuscripts at http://www.hindawi.com
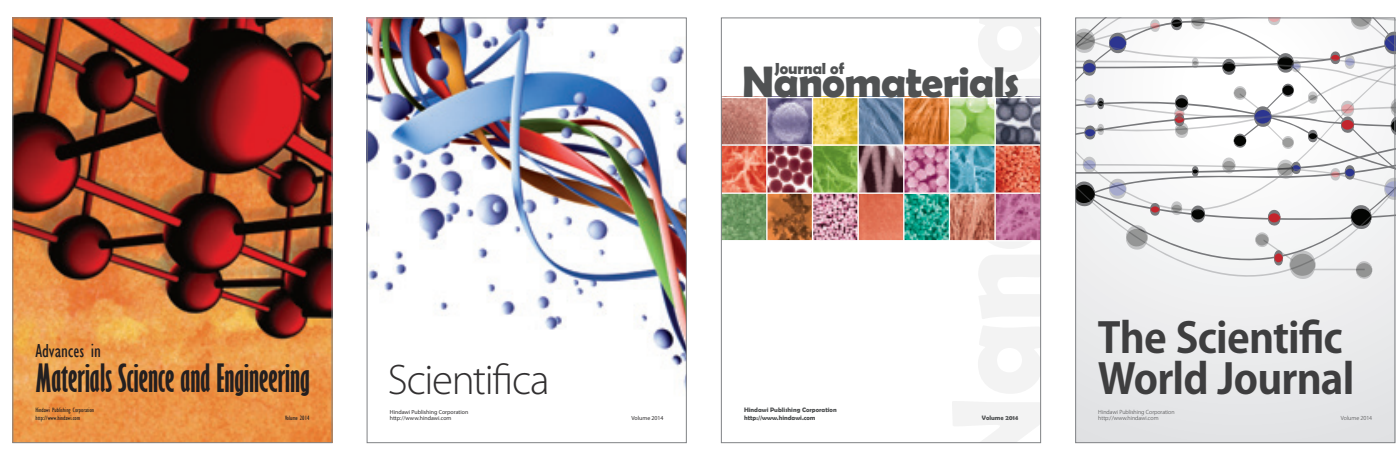

\section{The Scientific World Journal}
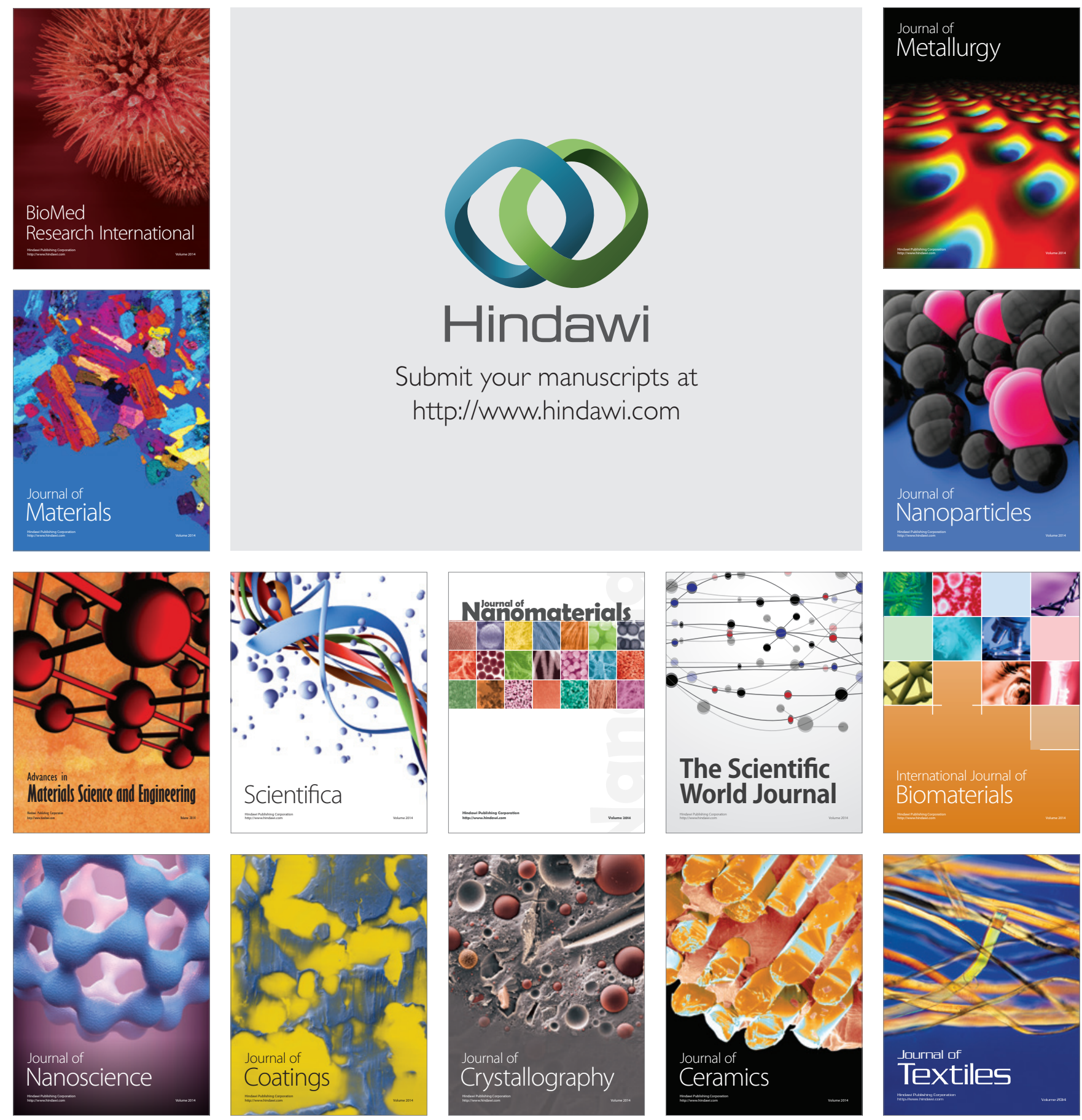